\title{
Vestibular Projections to the Thalamus of the Pigeon
}

\author{
Fritz W. VollRath and Juan D. DELIUS
}

Max-Planck-Institut für Verhaltensphysiologie, Abteilung Mittelstaedt, Seewiesen

Key Words. Pigeon - Thalamus - Unit recording · Vestibular projection

Abstract. Microelectrode recording in the thalamus of pigeons subjected to tilt and sinusoidal rotational stimuli around the vertical, longitudinal and transversal axes revealed vestibularly driven units in two thalamic nuclei, the nucleus posteroventralis and the nucleus principalis precommissuralis. Many of these units responded in a complex manner suggesting that inputs from contralateral and ipsilateral cupulae and maculae converged on them. A few units received additional visual or proprioceptive information. The homology relationship with a mammalian vestibular thalamic nucleus is discussed briefly.

\section{Introduction}

While the medullary and cerebellar projections of the vestibular system of birds have recently received some attention [Bojko and SMIRNOv, 1971; WILSON and FELPEL, 1972; WILSON et al., 1974; BOORD and KARTEN, 1974] nothing is known about such projections to more anterior portions of the neuraxis. The present study was initiated by an incidental discovery of vestibularly-driven units in the thalamus during an investigation of the somesthetic projection of pigeons [DeLIUs and BENNETTo, 1972] and motivated by a general interest in the sensory control of avian righting reflexes [MITTELsTAEDT, 1964; BIEDERMAN-Thorson and Thorson, 1973; Delius and Vollrath, 1973].

\section{Subjects and Methods}

23 adult pigeons (Columba livia) of local-homing stock were used. Each was anesthetized with Equithesin (intramuscularly, $0.30 \mathrm{ml} / 100 \mathrm{~g}$ body weight; supplemen- 
tary doses $0.10 \mathrm{ml} / 100 \mathrm{~g}$ ) and had its head mounted in an approximately normal attitude in a stereotaxic holder [KARTEN and HoDos, 1967]. For greater stability we used dental acrylic to cement the occipital portions of the skull, that had been pitted with a dental drill, to a brass crossbar. The headholder was mounted on a suspended, counter-weighted turntable that allowed rotation of the pigeon around its vertical (yaw), longitudinal (roll) and transverse (pitch) axis while its head remained centered. The body of the subject was bedded in a semicylindrical holder that could be independently tilted around the longitudinal axis with respect to the turntable and thus to the head. With the dental drill we also cut a small window into the skull over the target area.

Because of interfering eye muscle potentials related to the ocular reflexes elicited by the rotational stimuli when anesthesia was shallow, we recorded differentially from a pair of parallel tungsten electrodes with tips $0.5 \mathrm{~mm}$ apart. One of these electrodes was a microelectrode with a platinum-black-coated tip, either bought (Hear) or made by us with conventional methods. These microelectrodes had a $\sim 12 \mathrm{M} \Omega$ impedance at $1,000 \mathrm{~Hz}$. The other electrode of the pair was a macroelectrode made by scraping $0.5 \mathrm{~mm}$ of insulation off the tip of a microelectrode. The electrodes were advanced with a stereotaxic micromanipulator mounted on the turntable. The animal was grounded with a needle electrode inserted in the rump.

The potentials were amplified with a turntable-mounted, high-impedance, capacity-compensated preamplifier operating with a passband between 0.3 and $3 \mathrm{KHz}$ and an additional $50-\mathrm{Hz}$ notch filter. The output was monitored with an audio unit and an oscilloscope. A multichannel FM tape recorder registered the neuroelectric events as well as potentials deriving from the potentiometers attached to the turntable axles. These coded the tilting and turning of the table that was produced by hand. When appropriate, the tape-recorded data were filmed with an oscilloscope camera.

\section{Results}

The electrode penetrations were initially aimed at exploring the whole thalamus from stereotaxic coordinates A 4 to A 7.5, L 2 to L 5.5 and D 4 to D 8 [KARTEN and HoDos, 1967] but later, when we had identified a responsive region, we concentrated our efforts on the corresponding range of coordinates. While the electrodes were advanced, the animal was subjected sequentially to approximately sinusoidal yaw, pitch and roll rotations of about $1-\mathrm{Hz}$ frequency and about $90^{\circ}$ amplitude $\left(-45^{\circ}\right.$ to $+45^{\circ}$ off the normal position). We found a total of 89 units, or clusters of units that responded to this stimulation. 40 of these were studied in more detail. Judged by the shape and size of the action potentials on the photographic records they were either single units (23) (fig. 1) or clusters containing a few units behaving very similarly (17). For convenience, we shall, however, refer to all of them as units in the remainder of the paper. 


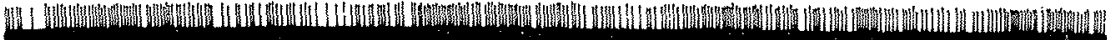

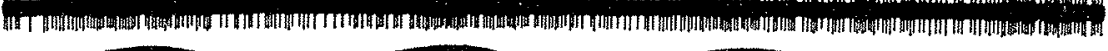

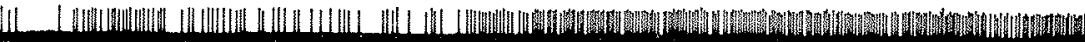

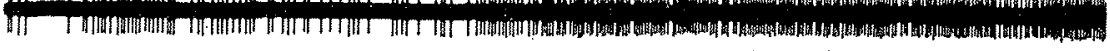

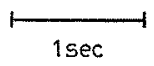

Fig. 1. Response of unit in the thalamus of a pigeon to rotational stimuli. Top: resting activity, normal position; middle: response to sinusoidal roll $\left(90^{\circ}, 45^{\circ}\right.$ to each side of normal position), upwards deflection of stimulus trace indicates rotation ipsilateral side downward; bottom: response to a $90^{\circ}$ nearly-step roll stimulus.

Throughout the investigations of these units, the head of each subject was covered with a light-tight head cap to avoid confusion with visually driven units. Suppression of all eye movements (absence of muscle potentials) by temporary deep anesthesia indicated that the units were not being driven by afferent feedback produced by nystagmus. Two typical rotation-sensitive units that were tested with auricular caloric stimulation, proved to be responsive to it: they were thus in all probability driven by vestibular mechanisms.

The 40 units were subjected sequentially to rotational roll, pitch and yaw stimuli (rate of rotation approximately $45^{\circ} / \mathrm{sec}$ ) to both sides of the normal position. A great variety of response modes was found (fig. 2). The majority of units (26) responded to yaw, roll and pitch stimuli. 9 units responded only to roll and pitch stimuli, 2 units to yaw and roll stimuli, 2 units to yaw and pitch stimuli and 1 only to yaw stimuli. Virtually all units (39) exhibited a resting discharge in the normal position. This, of course, may be due to experimental bias: units not showing such behavior were more likely to pass unnoticed when advancing the electrode even though we made some effort in testing 'silent' sites. Thus, all these units could potentially show two types of responses to rotational stimulation: an increase and a decrease in the firing rate.

In table $\mathrm{I}$, the units are classified according to their predominant responses as the pigeons were subjected to step rotations to one and then to 


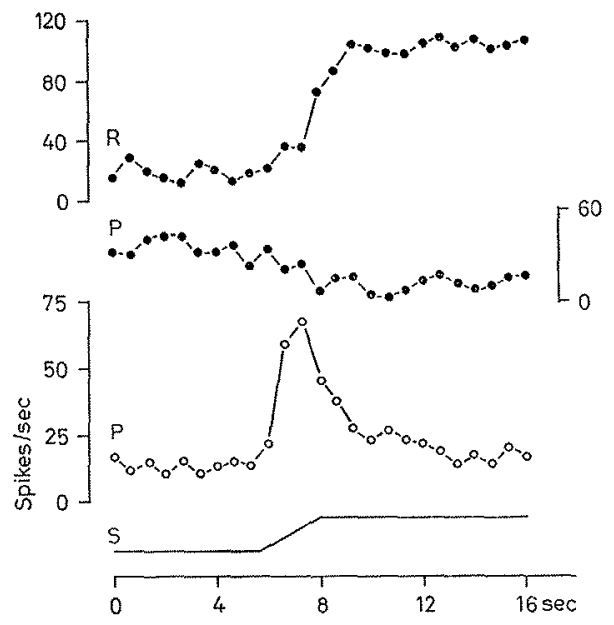

Fig. 2. Response of two thalamic units of a pigeon to partial rotations of $90^{\circ}$ amplitude. $-=$ Response of one unit to roll ( $R$, ipsilateral side downwards) and pitch ( $P$, head downwards); $O=$ response of a different unit to pitch ( $P$, head downwards); stimulus trace $(\mathrm{S})$ indicates the approximate time course of the rotation.

Table I. Activation-inhibition response patterns of vestibularly driven thalamic units of pigeons to step rotations to either side of the normal position

\begin{tabular}{lllll}
\hline & $\begin{array}{l}\text { Inhibition/ } \\
\text { activation }\end{array}$ & $\begin{array}{l}\text { Inhibition/ } \\
\text { inhibition }\end{array}$ & $\begin{array}{l}\text { Activation/ } \\
\text { activation }\end{array}$ & Total \\
\hline Yaw & 18 & 10 & 3 & 31 \\
Roll & 24 & 11 & 2 & 37 \\
Pitch & 23 & 10 & 3 & 36 \\
\hline
\end{tabular}

the other side of the normal position. Not included are a few units whose complex response to step rotations defied this simple classification (see below). Units that were activated when rotated one way and inhibited when rotated the other way predominate. A slightly higher proportion of these latter units (11 against 7) responded with activation when the head was rotated ipsilateral to the recording side during yaw stimulation. With roll stimulation 16 units against 8 responded with activation when rotated ipsilateral side downwards. In the case of pitch stimuli, 14 units against 9 responded with activation with head-upwards rotations. 


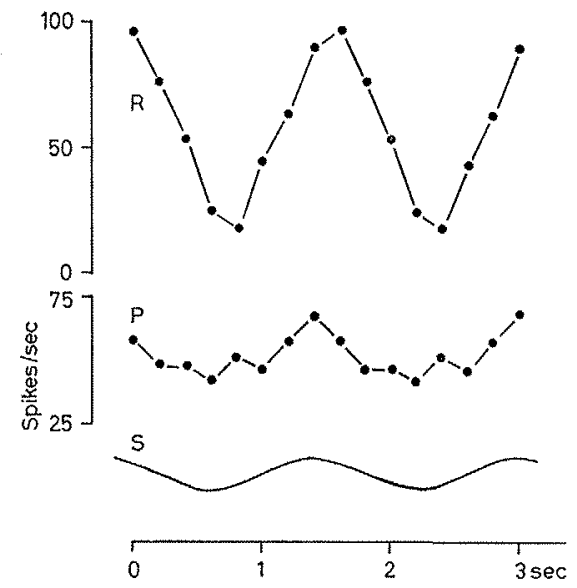

Fig. 3. Response of a thalamic unit of a pigeon to sinusoidal roll and pitch stimuli. Stimulus amplitude $90^{\circ}$ ( $45^{\circ}$ to each side of the normal position); upward deflection of the stimulus trace $S$ indicates an ipsilateral-side-downward (roll) and head-upward (pitch) motion.

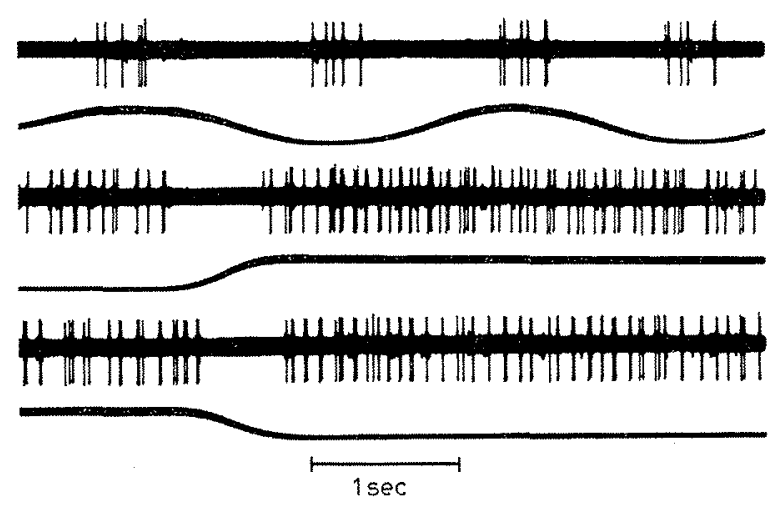

Fig. 4. Response of a thalamic unit of a pigeon to sinusoidal and step yaw rotations. Upward deflection of stimulus trace equivalent to clockwise rotation, amplitude of stimuli $90^{\circ}$.

With possibly one exception, the way in which a given unit responded to rotation around one axis did not allow one to predict how it would respond to rotation around another: all possible combinations of response types occurred and only a few units exhibited concordant behavior on stimulation around all three axes. The exceptions were 7 units that showed inhibition on turning to either side from the normal position with 
rotation around all three axes. These units occurred more frequently than one would have expected by chance (chance expectancy: approximately 2 units).

The above classification, however, does not really reflect adequately the variety of response patterns to step rotations we observed. Quite a few units, for example, responded to such stimulation with a sequence of inhibition and activation that made it difficult or even impossible to allocate the response to the categories of either inhibition or activation. Even when the responses were simple, their magnitude could vary considerably from one unit to the other, or even within one unit when it was stimulated by rotation around different axes. This was particularly obvious when the units were subjected to sinusoidal rotational stimuli (fig. 3). A unit might respond to both pitch and roll stimuli but the gain of the responses could differ appreciably. Some units behaved clearly non-linearly, as, for example, those that showed frequency doubling. For roll and pitch stimuli this kind of non-linearity is to be expected because of the cosine (or sine) transfer characteristic of the vestibular maculae [FERNANDEZ et al., 1972] but the occurrence of frequency doubling with sinusoidal yaw stimuli, presumably affecting only the semicircular canal cupulae, is less easy to interpret (fig. 4).

15 of the 40 units responded tonically to tilts around at least one axis, that is, they maintained, after a transient phasic response, a fairly constant rate of firing for at least $10 \mathrm{sec}$ or more for a given position. Most of these units (10) responded tonically to tilts around both the longitudinal and transverse axis, but some only responded tonically to stimulation around one axis and not at all or phasically to stimulation around the other axis. One remarkable unit showed an apparently tonic response to yaw motions!

For 5 such tonic units, we have some information about their behavior when the animals was rotated over $360^{\circ}$ by $45^{\circ}$ steps around the longitudinal and the transverse axis and held for at least $5 \mathrm{sec}$ in each position. The firing rate of these units was dependent on the static angular position of the subjects such that, for a given axis, there was one angular position yielding a maximal response and another position, about $180^{\circ}$ from the first, giving a minimal response (fig. 5).

While the type of stimulation used does not allow us to make a definitive statement, the behavior of the units suggests a good deal of convergence of cupular and macular input from both the contralateral and ipsilateral vestibula, 


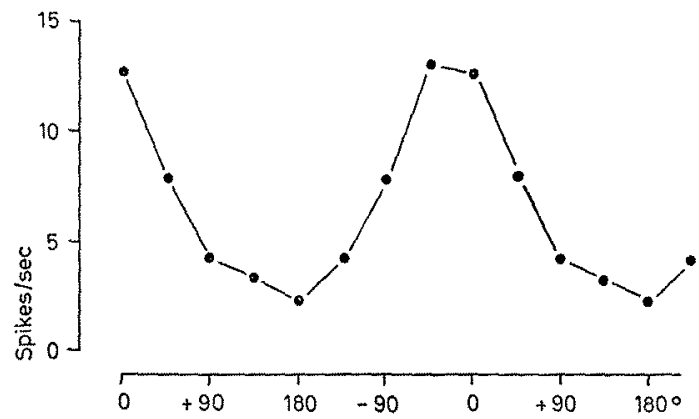

Fig. 5. Response of a thalamic unit of a pigeon to static roll positions. Each position was held $10 \mathrm{sec}$, the initial transients to position changes were disregarded and each point is an average of 3 measurements.

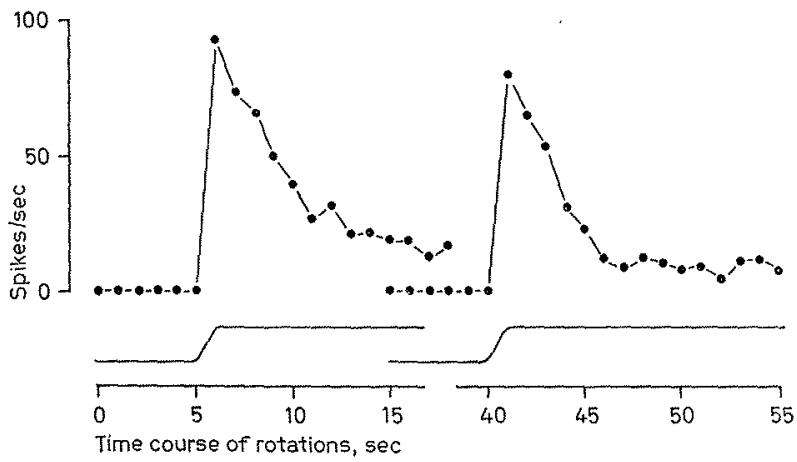

Fig. 6. Response of a thalamic unit of a pigeon to roll step stimuli affecting the whole animal (a) and the body alone (b). Stimulus trace indicates the time course of the rotation, upward deflection equivalent to an ipsilateral-side down motion.

12 of the units were also examined for sensitivity to roll stimulation of the body alone while the head remained immobile in the normal position: 2 units were found to be additionally responsive to this stimulation. Since they responded also to manipulation (bending, torsion) of the neck we suspect that neck mechanoreceptor signals, rather than visceral rotationsensitive inputs that we have described elsewhere [DeLus and VoLLRATH, 1973], converged on them (fig. 6). Qualitatively their functional properties conform with MitTELSTAEDT's [1964] postulates of vestibuloproprioceptive compensation in pigeons. We should mention that we also 


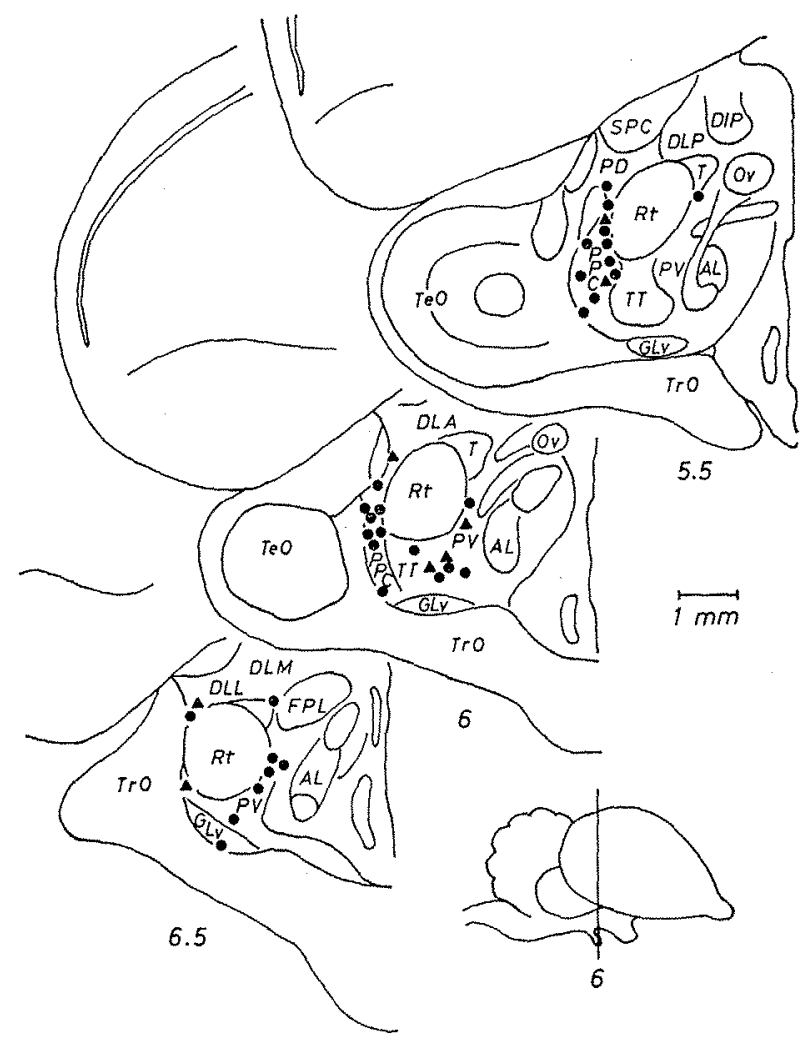

Fig. 7. Location of thalamic rotation-sensitive units of pigeons. $\mathbf{A}=$ Location of units marked with lesions. $\mathrm{AL}=$ ansa lenticularis; $\mathrm{DIP}=$ nucleus dorsointermedius posterior thalami; DLA $=$ nucleus dorsolateralis anterior thalami; DLL $=$ nucleus dorsolateralis anterior thalami, pars lateralis; DLM = nucleus dorsolateralis anterior thalami, pars medialis; DLP $=$ nucleus dorsolateralis posterior thalami; FPL = fasciculus prosencephali lateralis; GLv = nucleus geniculatus lateralis pars ventralis; $\mathrm{Ov}=$ nucleus ovoidalis; $\mathrm{PD}=$ nucleus pretectalis diffusus; $\mathrm{PPC}=$ nucleus principalis precommissuralis; $\mathrm{PV}=$ nucleus posteroventralis thalami; $\mathrm{Rt}=\mathrm{nu}$ cleus rotundus; $\mathrm{SPC}=$ nucleus superficialis parvocellularis; $\mathrm{T}=$ nucleus triangularis; $\mathrm{TeO}=$ tectum opticum; $\mathrm{TrO}=$ tractus opticus; TT $=$ tractus tectothalamicus: Brain section diagrams based on KARTEN and HoDos [1967].

came across a number of units that were responsive to body roll alone but not to rotation of the whole animal. These were probably part of the thalamic somesthetic projection, located by DeLIUs and BENNETTO [1972] in the region of the nuclei superficialis parvocellularis and dorsolateralis posterior, and were not studied in detail. 
We also found a large number of units responsive to light pulses. These were suspected to belong to the nucleus rotundus, a well-known visual tecto-thalamic projection [COHEN and KARTEN, 1974]. However, only one of the 25 rotation-sensitive units that we tested was responsive to this kind of visual stimulus. It responded with an 'on' and an 'off' burst of spikes to a light pulse but its resting activity was higher in the dark than in the light.

The location of 10 (all in different animals) of the 40 units was marked with a lesion by applying $9 \mathrm{~V}$ d.c. between ground and the macroelectrode. The heads of the animals with these lesions were perfused with saline and formalin through the carotids immediately after sacrifice. Later the brains were removed and $20-\mu \mathrm{m}$ frozen sections in the same plane as the stereotaxic transverse plane were prepared. These were stained with cresyl violet and the lesions located with the aid of a microscope. The positions of the units were recorded on stereotaxic map drawings, taking into account the tip location difference between the macroelectrode and the microelectrode. By comparing the actual location of these units with the stereotaxic coordinates noted for them during the recording experiment we could compute a correction vector for each of the 10 pigeons. These vectors were used to adjust the position of a further 29 units found in the same pigeons. Since the correction vectors were small (equal to or less than $1 \mathrm{~mm}$ ), the position of the remaining 10 units (from animals without marker lesions) was entered according to their uncorrected coordinates.

It is apparent that the units cluster either medially or laterally to the nucleus rotundus, the salient landmark of the avian thalamus. With reference to the KARTEN and HoDos [1967] atlas they lie, with 2 exceptions, within the nucleus posteroventralis thalami and the nucleus principalis precommissuralis (fig. 7). Attempts to relate the response behavior of the units with their location in one or the other of the nuclei were unsuccessful.

\section{Discussion}

Nothing appears to be known with certainty about the connections of these two nuclei. Thus we do not know whether the nuclei receive direct input from the metencephalic vestibular nuclei and whether they project to the telencephalon as would be expected of classical thalamic relay nuclei. We are also uncertain whether there is any significance in the fact 
that the rotation-sensitive units found by us are restricted to only the anterior portion of the nucleus posteroventralis. The account of the perirotundal region made by ARiËNS KAPPERS et al. [1960] suggests that the subdivision of this area is a difficult and contentious one. They mention a nucleus postrotundus that might be equivalent to the posterior portion of the principalis precommissuralis that we found to be similarly free of vestibularly driven units. They also mention that the posteroventralis nucleus is comparatively less developed in a non-flying bird (chicken), a circumstance that may have to do with the presumably reduced vestibular function in flightless birds.

In mammals the nucleus ventroposterior inferior has been recently identified as the thalamic vestibular nucleus which then projects to the vestibular cortex [DEECKE et al., 1973, 1974]. It is premature to consider possible homologies between this mammalian nucleus and the two thalamic vestibular nuclei we identified in the pigeon. But it is striking that, in pigeons, apparently two, rather than one thalamic mass, receive vestibular input and, furthermore, that relative to the remainder of the thalamus these nuclei appear to be large in comparison with the mammalian vestibular thalamus. It seems likely that this more extensive representation has again to do with the greater importance that vestibular information must have for flying animals.

\section{Acknowledgements}

We thank Dr. H. Mrtrelstaedt for his hospitality and his collaborators for the assistance they gave us. We are grateful to D. HARPER (Department of Psychology, Durham, UK) for help with the histology, and to Ms. J. EMMERToN (Department of Psychology, Swansea, UK) for criticism and correction of an earlier draft. Part of the research was supported by a Science Research Council (London) grant to J.D.D.

\section{References}

ARIËNS Kappers, C. U.; Huber, C., and CRosby, E. C.: The comparative anatomy of the nervous system of vertebrates, including man (Hafner, New York 1960).

BIEDERMAN-THorson, M. and THORSON, J.: Rotation compensating reflexes independent of the labyrinth and the eye: neuromuscular correlates in the pigeon. J. comp. Physiol. 83: 103-122 (1973).

Bojko, V. P. and SMIRNov, G. D.: Convergence of afferent influences on neurons of the pigeon vestibular nuclei. Fiziol. Zh. SSSR 57: 403-409 (1971). 
BooRd, R. L. and KARTEN, H. J.: The distribution of primary lagenar fibres within the vestibular nuclear complex of the pigeon. Brain Behav. Evol. 10: 228-235 (1974).

COHEN, D. H. and KARTEN, H. J.: The structural organization of avian brain: an overview; in GOODMAN and ScheIN Birds; brain and behaviour (Academic Press, New York 1974)

DEECKE, L.; SChWARZ, D. W. F., and Fredrickson, J. M.: Response pattern of vestibular thalamic neurons in the rhesus monkey; in Stanle Proc. 3rd Extraord. Meet. Barany Soc.: Equilibrium Research 3: 4-7 (1973).

DeECKE, L.; Schwarz, D. W. F., and Fredrickson, J. M.: Nucleus ventroposterior (VPI) as the vestibular thalamic relay in the rhesus monkey: field potential investigation. Expl Brain Res. 20: 88-100 (1974).

DeLrus, J. D. and Bennetro, K.: Cutaneous sensory projection to the avian forebrain. Brain Res., Osaka 37: 205-221 (1972).

Delrus, J. D. and VollRatH, F. W.: Rotation compensating reflexes independent of the labyrinth: neurosensory correlates in pigeons. J. comp. Physiol. 83: 123-134 (1973).

Fernandez, C.; Goldberg, T. M., and AbEND, W. K.: Response to static tilts of peripheral neurons innvervating otolith organs of the squirrel monkey. J. Neurophysiol. 35: 978-997 (1972).

Karten, H. J. and Hodos, W. A.: A stereotaxic atlas of the brain of the pigeon (Hopkins, Baltimore 1967).

Mrttelstakd, H.: Basic control pattern of orientational homeostasis. Symp. Soc. exp. Biol. 18: 365-385 (1964).

Wilson, V. J.; Anderson, J. A., and Felix, D.: Unit and field potential activity evoked in the pigeon vestibulocerebellum by stimulation of individual semicircular canals. Expl Brain Res. 19: 142-157 (1974).

Wilson, V. J. and Felpel, L. P.: Specificity of semicircular canal input to neurons in the pigeon vestibular nuclei. J. Neurophysiol. 35: 253-264 (1972).

J. D. Deurus, Psychologisches Institut, Ruhr-Universität, $D-4630$ Bochum (FRG) 